\title{
Contribution of Arbuscular Mycorrhizal Fungi (AM Fungi) and Rhizobium Inoculation on Crop Growth and Chemical Properties of Rhizospheric Soils in High Plants
}

\author{
Mugabo Jean Pierre ${ }^{1}$, Dr. Balkrishna Sopan Bhople ${ }^{2}$, Dr. Anil Kumar ${ }^{3}$ \\ Havugimana Erneste ${ }^{4}$, Byiringiro Emmanuel ${ }^{5}$, Yumnam Neeraj Singh ${ }^{6}$ \\ 1,2,3,4,5,6 (Department of Agriculture, Lovely Professional University, India)
}

\begin{abstract}
Soil microorganisms commonly named biofertilizers can be used to decrease input of fertilizers, pesticides and other chemicals in Agriculture. Among soil microorganisms, arbuscular mycorrhizal (AM) fungi and Rhizobium spp. can promote plant growth and control plant fungal diseases. However these microorganisms are not yet used in commercial biocontrol products. Integration of Arbuscular Mycorrhizal Fungi with Rhizobium sp. thus appears to be a promising approach for sustainable agriculture especially in legume crops where the net influence of this combination is supposed to be very high compare to other types of crop families. Arbuscular Mycorrhizal fungi and root-nodule bacterium Rhizobium are two root symbionts. Arbuscular mycorrhizal fungi increases soil nutrients and water absorption, while root-nodule bacteria fix atmospheric nitrogen and produce antibiotics and phytoalexins. These microbes modify the quality and abundance of rhizosphere microflora and alter overall microbial activity of the rhizosphere. They induce changes in the host root exudation pattern. A procedure for successful development of these microorganisms is required by selection and screening of efficient isolates. Knowledge of culture systems that are adapted to their establishment and multiplication is needed. Arbuscular mycorrhizal fungi provide specific niches for bacteria. Arbuscular mycorrhizal bacteria improve nutrient acquisition in plants and subsequently, growth of the particular crops is advantaged indeed. Arbuscular mycorrhizal bacteria may contribute to ability of arbuscular mycorrhizal fungi to inhibit pathogens acquire mineral nutrients and modify plant root growth. Combined use of these microorganisms is more beneficial than their use alone. Together, they Influence plant root morphology changes and chemical properties of Rhizospheric soils of high plants with the significant extent. These symbionts also interact with other beneficial microorganisms synergistically and can be exploited for sustainable agriculture. The sound influence of these symbionts on root morphology and growth of the whole crop as well as on soil properties interested many researchers in agriculture domain.
\end{abstract}

Keywords: Arbuscular Mycorrhizal Fungi, Crop Growth, Rhizobium, Rhizospheric soil, Soil Properties

\section{Introduction}

The greatest challenge of $21^{\text {st }}$ century in many developing countries is to produce the basic necessities namely food, fuel and fiber for human consumption and fodder for rearing domestic animals from the limited available land without soil degradation and at the minimum amount of agriculture inputs. The availability of land for agriculture is shrinking everyday as it is increasingly utilized for non-agriculture purposes while physical and chemical properties of soils are day to day changing improperly which affect production and suitability of the soil to different many crops. Under this situation, one of the important strategies to increase agriculture production as well as to improve and sustain soil properties is the development of high use efficiency of all sources of nutrients available. Most of higher plants have the ability to form arbuscular endomycorrhiza (AM); a symbiotic association of the plant root with fungi belonging to the order of Glomales. These fungi grow towards the inner cortical cells of the root where they differentiate into highly branched structures, the arbuscules. In AM symbiosis, the fungus also forms hyphae outside the plant and these provide a connection between the soil and the inner part of the plant and they facilitate the uptake of nutrients such as phosphate [1]. In contrast to $\mathrm{AM}$ formation and establishment, only a few plant species have the ability to interact symbiotically with bacteria of the genera Azorhizobium, Bradyrhizobium, Rhizobium and Sinorhizobium (here collectively called Rhizobium). This interaction is almost completely limited to leguminous plants and results in the formation of a completely new organ, the root nodule. In these nodules the bacteria are hosted intracellularly and there they find the ideal environment to reduce atmospheric nitrogen into ammonia, a source of nitrogen which can be used by the plant [2]. Furthermore, some host genes are induced during the initial steps of both interactions. In the first part of this overview, the rhizobium-plant interaction is described with an emphasis on factors that determine the specificity of the interaction. In the second section, AM formation is described as well as the common aspects of both symbioses. Dual inoculation with both rhizobium and AM Fungi results in a tripartite mutualistic symbiosis and increases plant growth to a greater extent than inoculation with only one of 
them [3]. Soil microorganisms are paramount in the biogeochemical cycling of both inorganic and organic nutrients in the soil and in the maintenance of soil quality. In particular, microbial activity in the rhizosphere is a major factor that determines the availability of nutrients to plants and has a significant influence on plant growth as well as soil health and productivity. It is very important to understand the basic principles of rhizosphere microbial ecology, including the function and diversity of the microorganisms that reside there, before soil microbial technologies can be applied. Both rhizoidal and mycorrhizal symbioses share some signaling pathways, indicating intimate interactions between all three partners during co-evolution [4]. Generally, the rhizospheric soil contains many types of microorganisms such as bacteria, actinomycetes, fungi, and algae. These are important microorganisms because they affect the soil's physical, chemical, and biological properties. The plant root-soil interface is a dynamic region in which numerous biogeochemical processes take place driven by the physical activity, and the diversity of chemicals released by the plant root and mediated by soil microorganisms. Understanding and harnessing the influence of AM fungi and Rhizobium inoculation on growth of the crop, root morphology and chemical properties of Rhizospheric soils in was the challenge of this review.

\section{Soil And Rhizosphere}

Many soil microbes originate in the soil or are closely associated with the soil environment and have substantial impact on mankind [5]. Soil microorganisms inhabiting the Rhizosphere environment interact with plant roots and mediate nutrient availability, e.g. those forming useful symbiotic associations with the roots and contribute to plant nutrition and chemical properties of the soil. Implications of plants and their symbionts like mycorrhizal fungi, $\mathrm{N}$-fixing rhizobia, and free living rhizosphere population of bacteria which promote plant growth need to be fully exploited and encouraged by inoculating nutrient poor agricultural soils with appropriate microbes [6]. The plant Rhizosphere is the major soil ecological environment for plant-microbe interactions involving colonization of different microorganisms in and around growing roots which may either result in associative, symbiotic, neutralistic, or parasitic interactions depending upon plant nutrient status in soil, soil environment, plant defense mechanism, and the type of microorganism proliferating in the rhizosphere zone. Finding the microorganisms very close to epidermis, plants secrete signal molecules for protection against invasion of the heterogeneous microbes in the root zone, and at this stage the differentiation takes place between pathogenic, associative, symbiotic, or neutralistic adaptation of microbes with the plant [7]. The plant signal molecules produced in response to microbial adhesion are the flavonoids and flavones which are secreted in the rhizosphere bacteria and some remain attached to plant cell walls to act as antimicrobial agents (phytoalexins). In legume-Rhizobium symbiosis, the rod-shaped soil bacterium, Rhizobium, induces nitrogen-fixing nodules on the roots of leguminous plants. In this process, dinitrogen which is chemically inert and makes up approximately $80 \%$ of the volume present in the earth's atmosphere is reduced to ammonia by the bacterial enzyme nitrogenase.

\section{Microbial Inoculants And Biofertilizers}

Traditional use and importance of chemical fertilizers in agricultural production cannot be over emphasized, but with fertilizer costs going up, their effect on plant and soil chemical properties and health, generally in parallel to increase in energy costs, these need to be supplemented or substituted with cheaper available alternatives such as beneficial microbial inoculants, biofertilizers and organic amendments to improve soil quality, fertility, biology and agricultural productivity due to greater production of the crops[8]. Biofertilizers contain different types of microorganisms, which have an ability to convert nutritional important elements from unavailable to available for through biological processes in soil [9]. Biofertilizers have emerged as a potentially important component of the integrated soil nutrient supply system and hold great promise to improve crop yields [10]. Microbial inoculants and biofertilizers are an important component of organic farming accounting for about $65 \%$ of nitrogen supply of crops worldwide. In comparison with chemical/synthesized pesticides and fertilizers, microbial inoculants for biofertilizers have several advantages [11] including: Greater relative safety Potentially reduced environmental damage and human health risk, Mulch more targeted activity, effectiveness in small quantities, capacity for self multiplication while being controlled by the plant as well as by indigenous microbial populations, faster decomposing than conventional or integrated pest management system and ability to be used in conventional or integrated ; pest management systems.

\section{Mycorrhiza And AM Funfi}

Majority of plants growing under natural conditions have fungal associations with their roots and such 'fungus-roots' are called mycorrhizae. The mycorrhizae may be categorized as ectotrophic or endotrophic according to the major area of fungal colonization in the roots. The fungal partner in endotrophic mycorrhizae may belong to different groups. The endotrophic mycorrhizae formed by the non-septate phycomycetous group is called vesicular-arbuscular (VA) mycorrhiza [12].Vesicular arbuscular mycorrhiza (VAM) represents a 
symbiotic fungal association. VA mycorrhiza occurs on most of the plants and is found in extremely diverse groups of them; moreover, they are common among a large number of agricultural crops. Since certain species of VAM fungi do not have vesicles, Arbuscular Mycorhhizae (AM) is the better general term for those species. The association between AM fungi and plants evolved through ages and has attained the present status. Although the interactions between AM fungi and host plants are well documented, the details of ecology of mycorrhizal fungi, especially the dynamics of AM fungi within roots as well as in the soil are yet to be studied. Therefore, detailed studies of AM fungal relationships with crops are essential for successful utilization of them in plant growth promotion and sustainable soil management procedures. AM fungi are cultured and survive with the presence of their host system and are therefore obligate associates within their host plants. As research on mycorrhizae is in progress all over the world, new species are added to the list of AM fungi (AMF) and at present the total number of species is about 200.

\section{1. general soil characteristics and amf}

\section{Factors Influencing AM Development}

It was reported the effect of edaphic factors on AM fungi and revealed that indigenous strains of mycorrhizal fungi are more adapted to the edaphic factors, and AM fungal strains that are more efficient but alien to the local environment may not perform well due to lack of adaptation [13]. Among different soil parameters, soil texture influence spore germination and hyphal growth so that any specific AM population develops according to the prevailing soil texture. It was reported that cultivation of host plants favour increased sporulation, while non host plants decrease them; increased $\mathrm{N}$ fertilization and fungicides caused inhibition of sporulation in AM fungi. It was suggested that chemical fertilizer application of the soil leads to establishment of inferior mutualistic AM fungi and hence reduced benefits to the host plant. Effect of soil toxicity on development of mycorrhiza in tree nurseries was reviewed [13].

\section{2. fertilizers and organic substances}

Application of super phosphate to mycorrhizal plants stimulated sporulation of P-tolerant AM fungi, while others resulted to the reduction in sporulation. Soil fertility affects soil-plant interaction, which in turn affects plant-fungus interaction and could subsequently affect mycorrhizal colonization and spore numbers [13]. It was reported that AM colonization became inhibited with cellulose amendment of soil [14]. AM spore density, percentage infection and intensity of infection were increased by organic amendments.

\section{3. soil moisture}

Soil moisture influences the AM infection in roots and the distribution of spores [15]. The paucity of infection developing in waterlogged soil is probably due to insufficient oxygen. Water logging substantially reduces the number of spores in mangrove soil and abolishes mycorrhizal infection. Poor sporulation and root colonization were noticed in high moisture availability.

\section{4. biotic communities, crop rotation and community succession}

There are reports on the effect of root exudates of high plants on mycorrhizal infection. Absence of sugar in the root exudates of some wheat varieties resulted in the absence of mycorrhizal infection. AM infection contributed to the decreased total sugar content of the root of wheat. Crop rotation causes large changes in mycorrhizal fungal communities. The effect of crop rotation on diversity and functionality of AM fungi was reported [16]. This is due to the fact that biotic factors exist in non-treated agricultural soils that influence the sporulation and inoculum density of AM fungi.

\section{Endomycorrhizal Symbiosis And Common Aspects Of Both Interactions}

In nature, most plants do not only have roots; instead they have mycorrhizae, the symbiotic association of a fungus and plant roots. AM are by far the most common root endosymbiotic association, and are formed between the roots of most higher plants and fungi belonging to the order Glomales. AM fungi are obligate biotrophs and strictly dependent on their host plant for survival. As with the Rhizobium-legume interaction, this symbiosis is set in motion by the exchange of signals between the two symbionts, although the nature and the mechanism of action of these molecules are unknown. Exudates from a host root, especially (iso) flavonoids, enhance spore germination, and elongation and branching of hyphae [16]. The plant accommodates the invasion of the fungus by secreting new cell wall material which surrounds the infecting hyphae. In the inner cortex, the fungus invades cells and there they differentiate into highly ramified structures, the arbuscules (Fig). These structures are thought to facilitate the exchange of nutrients between both organisms. Although arbuscules occur intracellularly, they are never in direct contact with the cell cytoplasm. A perifungal membrane, originating from the plant plasma membrane invaginates and surrounds the arbuscules. During the formation of arbuscules, 
the plant cell becomes cytoplasmically dense, its vacuole fragments, and the number of Golgi bodies increases. Furthermore, the nucleus moves to a more central position in the cell [17].

\section{1. interactions between am fungi and host plants}

Mycorrhiza represents physiologically well balanced reciprocal relationships and without mycorrhizal associations most plants would not be able to survive in the competitive communities found in natural soil habitats. Mycorrhizal fungi through cohabitation with plant roots have developed a more secure food supply [16]. Plants receiving a balanced nutrient solution without $P$ consistently had the greatest percentage of root length colonized by AM fungi. It was confirmed the carbon transfer between the root system of neighbouring plants connected by common mycorrhizal network [18]. The interplant hyphal bridges formed by VA mycorrhizal mycelia and confirmed that AM infection can provide channels for direct interplant nutrient transfer. It was found that plant nitrogen stress affects the host root colonization by AM fungi [19]. According to the same authors, nutrient transport in mycorrhizal symbiosis is bidirectional, with flux of phosphate to the plant and carbohydrate to the fungus across specialized plant-fungus interfaces which indicates a carbon drain from the host, but that does not affect the productivity of the host as the mycorrhizal association enables better nutrient and water absorption.

\section{2. am fungi and root relationships}

AM fungal hyphae can prolong viability after root death and dried mycorrhizal roots can act as propagules [20]. In terms of morphogenetic modification induced by the AM mycorrhizal fungus in the host root system, it was observed that the roots of mycorrhizal plants became progressively more branched, branching increased linearly with mycorrhiza, and there is significant reduction in the mitotic index in the apical meristems of AM infected roots [21]. Moreover, the roots become numerous and shorter in AM infected plants than those of controls. beneficial effect of mycorrhiza is of special importance to those plants having a coarse and poorly branched root system since the external hyphae can extend as much as $8 \mathrm{~cm}$ away from the roots, absorb nutrients from a much larger soil volume than the absorption zone surrounding non mycorrhizal roots. Research reported that root hair length and abundance are good predictors of the beneficial effect of Glomus species [22]. It was observed that alteration of root longevity can be induced by AM fungi and colonized roots survived for a shorter period than non-colonized roots [23].

\section{3. am fungal colonization and its importance to the host plants}

Studies on AM fungal colonization in different plants by different AM fungi have come out with differential responses. Research reported that plants receiving balanced nutrient solution without $\mathrm{P}$ consistently had the greatest percentage of root length colonized by AM fungi[24]. They observed that soy bean roots from most soils in spite of some soils having very high soil P levels were extensively colonized by AM fungi. AM fungi associated with plants on the burned sites are likely to be a carbon drain on the host plants and may not benefit from their AM fungal association especially early in the growing season. Various aspects of mycelium of different genera of AM fungi. According to them the coexistence of several species of AM fungi belonging to different genera may lead to various states of compatibility between the fungus and the plant depending on the growth phase and physiological state of the host plant. They also emphasized the need of further in-depth studies of disturbed plant ecosystems to assess the real factors responsible for stable symbiotic relationships in mycorrhiza. It is suggested that there is an incompatible reaction between non-mycotrophic annual and AM fungus, where the plant actively rejects infection [25].

\section{4. am and plant growth responses}

Inoculation of AM fungi had no effect on shoot dry weight, but increased area and dry weight of leaf blades and caused higher rate of transpiration in AM plants [26]. In common beans the increase in leaf area due to mycorrhizae and increased soil application of $\mathrm{P}$ were similar. It was observed that diversity of AM fungi in the soils might contribute to high crop productivity as the plants with mycorrhizal colonization may be able to resist environmental stresses better. It was also found that effects of mycorrhizal inoculation varied from soil to soil depending on the extent to which the effectiveness of indigenous and introduced endophytes was enhanced by P optimization. Subsequently, same others reported significant increase of dry biomass of Acacia nilotica inoculated with AM. During early stages of colonization the AM fungi may trigger the defense mechanism of the host plant that enables protection against root pathogens in cabbage [26]. Significant increase in the dry weight and $\mathrm{P}$ content of Amorpha crenulata and Jacquemontia reclinata due to AM fungi in native soil low

\section{5. am fungi and rhizosphere microorganisms}

Mycorrhizal inoculation could improve plant utilization of sparingly soluble tricalcium phosphate. But PSB inoculation could not improve phosphatic fertilizer utilization. However, PSB inoculation resulted in 
increased shoot nitrogen content and increased mycorrhizal infection. It was shown direct and indirect effects of AM fungi and rhizosphere microorganisms on acquisition of mineral nutrients by maize and found that mycorrhizal treatments enhanced the uptake of $\mathrm{P}, \mathrm{Zn}$ and $\mathrm{Cu}$. Bacteria from rhizosphere and hyphosphere soils of different AM fung were reported [27]. More bacterial species were encountered in hyphosphere than rhizosphere, but bacterial numbers were greater in rhizosphere than hyphosphere soil. The development of AM fungal mycelium in soil had little influence on the composition of the microflora of hyphosphere, while AM colonization was positively related with bacterial numbers in hyphosphere. They observed that AM fungi and other rhizosphere organisms interacted positively and affected the acquisition of other nutrients mostly through alteration of root morphology.

\section{6. role of am in other mineral absorption}

The rate of uptake of nutrients by the plants may be limited by its rate of diffusion through the soil .Hyphae of AM fungi, which extend beyond the plant rhizosphere can take up $\mathrm{N}$ and transport it into the rooting zone and this can increased uptake of $\mathrm{Zn}, \mathrm{Mn}$ and Fe in plants due to the inoculation with AM fungus Glomus fasciculatum [28]. According to them promotion of plant growth with the help of mycorrhizal infection may be through direct acquisition of nutrients by the fungus or indirectly by modifying transpiration rates and the composition of rhizosphere microflora. They also reported in soybean that, at low and medium P levels the root AM fungal colonization and growth of root nodules increased in the presence of Rhizobium. They also realized that $\mathrm{AM}$ and rhizobial treatments had a tendency to suppress the acquisition of seed $\mathrm{Al}, \mathrm{Cu}$ and $\mathrm{Fe}$. Low input agricultural systems that do not rely on fertilizers might be more dependent on AM fungi than conventionally managed systems [29]. According to [28] plants can adapt to changing soil nutrient levels by shifting their dependence on AM fungus. In wheat high AM colonization Corresponded with reduced Mn uptake and reduced grain $\mathrm{Mn}$ concentration and did not correspond with crop growth, yield or uptake of $\mathrm{P}, \mathrm{K}, \mathrm{Ca}, \mathrm{Cu}$ or $\mathrm{S}$ in wheat or pea [29].

\section{Rhizobia}

Rhizobia are special bacteria that can live in the soil or in nodules formed on the roots of legumes. In root nodules, they form a symbiotic association with the legume, obtaining nutrients from the plant and producing nitrogen in a process called biological nitrogen fixation, or BNF. The rhizobia are broadly classified as fast- or slow-growing based on their growth on laboratory media. Rhizobia are further classified according to their compatibility with particular legume species. Farmers can stimulate BNF by applying the correct rhizobia to their legume crops, a process called inoculation. The module describes the diversity of rhizobia and the selection of superior strains, as well as plant and environmental factors that affect rhizobia in the soil.

\section{1. the iimportance of native rhizobia}

It is important to consider the numbers and types of native rhizobia in the soil because they can affect the results of inoculating legume seeds with introduced rhizobia. Remember that native rhizobial populations are diverse, containing effective and ineffective strains. These native rhizobia can affect the results of inoculation in two ways. If there are already many native rhizobia in the soil that can nodulate a legume crop and induce BNF, then inoculating seed may not produce any further benefits. For example, if a farmer has grown peanuts for some years, there may be many native rhizobia in the soil that are effective on peanut. Adding more rhizobia in an inoculant may not make any difference. On the other hand, native rhizobia may compete with introduced rhizobia to form nodules on legume plants. In this case, the nodules on the legume are formed by the native rhizobia and not by the rhizobia introduced in the inoculant. If the native rhizobia are not as effective at fixing nitrogen as the introduced strains, then plants will not get the maximum benefit from BNF.

\section{2. rhizobium-induced nodule formation nod factors}

Root-nodule formation involves growth responses in the epidermis as well as cortex of the root. This implies that the bacteria redirect the development of fully differentiated plant cells. The bacterial signals that set this in motion are the so-called nodulation (Nod) factors. Nod factors of the different Rhizobium species have a common basic structure; a b-1,4-linked N-acyl-D-glucosamine backbone of mostly four or five units, containing a fatty acid at the non-reducing terminal sugar [30]. The biosynthesis of the basic Nod-factor structure is catalysed by the bacterial NodA, NodB and NodC proteins. NodC is an N-acetylglucosaminyl-transferase and catalyses the synthesis of the chitin oligomer and controls the length of this backbone. The terminal nonreducing glucosamine unit of this oligomer is deacetylated by NodB, and subsequently substituted with an acyl chain by NodA. Several other Nod proteins, which can be specific for a certain Rhizobium species, modify a terminal sugar residue or determine the nature of the acyl chain [31]. These modifications define the biological activity and host specificity (see below) of Nod factors. The major difference between both Nod factors concerns the presence of a sulfate group at the reducing terminal sugar of the S.meliloti factor and the structure 
of the acyl chain. Since bioactivity of Nod factors is controlled by their structure it is very likely that they are recognized by receptors of the host. However, such receptors have not been cloned. Biochemical studies have shown that a few Nod-factor binding proteins occur, but it is not yet clear whether these are Nod-factor receptors [32].

\section{3. nodulation process}

Nod-factor-secreting rhizobia induce 'shepherd's crook'- like curling of root hairs within 1-2 days of inoculation (Figure1). Rhizobium uses the microenvironment within such curls to establish an infection site. They locally degrade the plant cell wall and enter the root hair via invagination of the plasma membrane [33]. Vesicles are directed to the invaginated membrane, leading to the formation of an 'inward tip growing' tubular structure, the infection thread (Figure 1). In general, Nod factors are not sufficient to trigger root-hair curling and infection-thread formation, but they play a crucial role in the infection process, since infections can only be initiated when the bacteria secrete specific Nod factors [34].

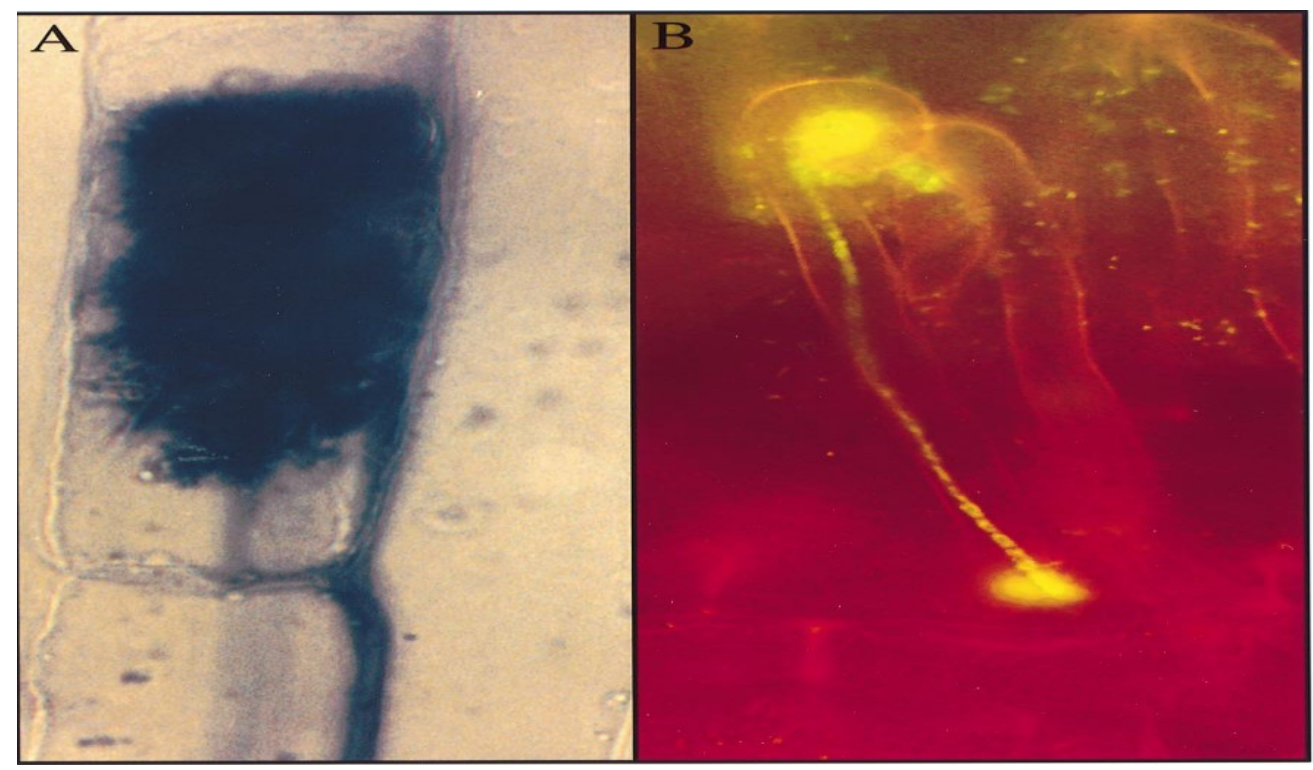

Fig. 1. Pea root cortex infected by the mycorrhizal fungus Glomus intraradices (A) and a Rhizobium leguminosarum bv viciae induced infection thread in a vetch-root hair (B). The AM fungus has entered the root intercellularly and it has formed an arbuscle [(A), Trypan blue staining]. In contrast, Rhizobium enters its host plant intracellularly via an infection thread [(B), Vetch-root hair with an infection thread containing R.leguminosarum bv viciae bacteria expressing green fluorescent protein (GFP) [35].

Results obtained with bioassays have provided some insight into the mechanism by which Nod factors alter the growth pattern of root hairs. Such studies have most extensively been carried out using vetch (Vicia sativa). Vetch-root hairs which respond morphologically to the application of Nod factor have almost terminated growth. The morphological changes start with swelling of the root hair tip, which occurs within $1 \mathrm{~h}$ of Nodfactor application. This swelling is the result of isotropic growth, is accompanied by the formation of a calcium gradient at the plasma membrane and requires protein synthesis. At these swollen tips, new tip growth is initiated and the cyto-architecture of the resulting outgrowth shows a strong resemblance to that of normal growing root hairs. Such studies show that Nod factors can re-induce (tip) growth in root hairs. However, it remains unclear how Nod-factor secreting bacteria can redirect tip growth in such way that shepherd's crooklike curls are formed. Furthermore, whether/how the bacteria exploit and modify this growth process for infection-thread formation remains to be resolved. Nod-factor-induced growth responses in root hairs are preceded by rapid physiological changes.

\section{Dual Inoculation Of AM Fungi And Rhisobium And Their Importance}

\section{1. innoculum production of am fungi and rhizobium}

AM fungi and Rhizobium had the capability to increase soil nutrients and water absorption as plant symbionts and also protect the plants from root pathogens under different pathosystems [36]. Beside these microorganisms also offers an alternative to chemical control and now used as a potential tool in the moderns agricultural system. The main obstacle is to produce large quantities of inoculum because of their obligate nature. The large-scale productions of AMF inoculums require control and optimization of both host growth and 
fungal development. The microscopic sizes of AMF, together with the complex identification processes also contribute to the pitfalls of inoculum propagation. The inoculum propagation process entails the following stages.

1. Isolation of AMF pure culture strain.

2. Choice of a host plant.

3. Optimum growing conditions

The use of Rhizobia with mycorrhizal fungi is more beneficial for reducing the damage caused by pathogens [36] as well as improving soil characteristic parameters and crop quality produce.

\section{2. am fungi and rhizobium with soil component}

Microorganisms in the soil constitute less than $0.5 \%(\mathrm{w} / \mathrm{w})$ of the soil mass; yet they have major impact on soil properties and processes [37]. Soil microflora constantly interacts with each other and such interactions are very dynamic in nature. Microbe-microbe, plant-microbe, soil-plant, and soil-plant-microbe interactions are very important in crop production under field conditions. Interestingly, majority of the root systems of the legumes are naturally infected with arbuscular mycorrhizal (AM) fungi, which augments efficient uptake of phosphorus from the soil. In legume plants the importance of AMF symbiosis has been attributed to high phosphorus requirements and enhanced phosphorus uptake. Soil microorganisms produce a certain a number of extra cellular enzymes to break down organic matter before being absorbed by the crop. There are quite variations in enzymes activities point of view especially in forest soils to bear correlation with fungi and bacteria [38]. In additional to this, much has been done and shared on the interactions of rhizobia for grain legumes in particular and for some tree legumes but little is known as the response of tree legumes [39].

\section{3. interaction of rhizobium with mycorrhiza}

The role of mycorrhizal fungi, especially the arbuscular mycorrhizae (AM fungi) belonging to the Zygomycetes class in phosphorous mobilization in soils having a relatively low level of available phosphorous, is well established for cereals as well as legumes. AM fungi are obligate symbionts but they are not host specific. Associative actions of mycorrhizal fungi in legumes has a great impact on root and shoot development and phosphorous uptake which results in the enhancement of nodulation and nitrogen fixation. There are several studies reporting the interactions between AMF and Rhizobium sp. [16]. Research has provided evidence that the genetic pathway of AM symbiosis is shared in part by other root-microbe symbioses such as N2-fixing rhizobia [40]. This specific relationship between AM fungi and Rhizobium provided an insight into specific functional compatibility interactions between AMF and their management when used as biofertilizers or biocontrol agents.

\section{4. role of am and rhizobium on other nutrients absorption}

The rate of nutrients uptake may be modulated by the presence or absence of AM Fungi or Rhisobium inoculation in leguminous crops. Hyphae of AM fungi into root zones extend even beyond the plant rhizosphere and take up nutrients well as transport it into the rooting zone. AMF contributed substantially to $\mathrm{Cu}, \mathrm{Zn}$ and $\mathrm{Cd}$ uptake in bean [28]. AM Fungi and rhizoidal combination suppressed the tendency for the acquisition of seed $\mathrm{Al}, \mathrm{Cu}$ and $\mathrm{Fe}$. They found that low input agricultural systems that do not rely on fertilizers might be more dependent on AM fungi than conventionally managed systems. According to [28] plants can adapt to changing soil nutrient levels by shifting their dependence on AM fungus and rhisobium. The fixation capability of rhisobium is a factor in sustainable agriculture point of view. Nitrogen is fixed and then enriches the soil in terms of nitrogen and thus soil properties are subsequently improved.

\section{5. am-rhizobium interaction and nitrogen nutrition}

Legumes are primarily known for their ability to fix nitrogen with the help of root nodule bacterium, Rhizobium. Mirrer, R.M., and Jastrow, J.D. 2000 reported increase in nodulation and nitrogen fixation in legumes following inoculation with mycorrhiza. They found that prior inoculation of one entophyte either AM fungus or Rhizobium, inhibited the development of the other in soybean. He also exploited the GlycineGlomus-Rhizobium symbiosis and found that micro-symbiont structures and nodule activity were significantly lower in tripartite combination than in plants colonized by only one symbiont. Dual inoculation with AM fungi and rhizobium enhances rates of mycorrhizal colonization, shoot dry weight, $\mathrm{N}$ and $\mathrm{P}$ content and nitrate reductase activity in comparison with inoculation the single bioferilizer or without inoculation [41].

\section{6. nodulation in relation to rhizobium, am fungi and other soil factors in legumes}

The root systems of leguminous plants are characterized by nodules harbouring nitrogen fixing bacteria Rhizobium. The nodulation and nitrogen fixation are controlled by many factors. The host genotype and Rhizobium as well as AM Fungi strains are critical in nitrogen fixation. It was also found that tropical legumes 
showed poor growth due to increase in Phosphorus concentration and excessive temperature, which inhibits symbiotic $\mathrm{N}$ fixation. The interaction of different factors influences the nodulation and nodule colonization of leguminous plants.

\section{Am-Rhizobium And Changes In Root Growth And Morphology}

The colonization by AM fungi results in morphological changes to the root, leading to an increased surface area of root [42]. Roots are the structural support of the plants and play the paramount role in absorption of water and supply mineral nutrients for a wide range of microorganisms. Changes in root morphology will ultimately affect the plant's responses to other organisms and influences the crop health. AM fungal-colonized roots are more highly branched which means that the root system contains shorter, more branched, adventitious roots of larger diameters and lower specific root lengths [43]. When plants are AM inoculated, they possess a strong vascular system, which imparts greater mechanical strength to diminish the effects of pathogens. The Rhizobium had the ability to increase the nodulation in leguminous plant which increases in plant vigor besides protecting roots from the attack of pathogen.

\section{Rhizobacterial Factors In CROP GROWTH Promotion}

Research on the use of rhizobacteria to promote plant growth (legumes as well as non-legumes) has increased dramatically over the last few years due to potential benefits observed in the use of PGPR or NPR, both under cultural conditions as well as under field conditions. A diverse array of bacteria, including species of Pseudomonas, Azospirillum, Azotobacter, Bacillus, Klebsiella, Enterobacter, and Serratia has been shown to enhance plant growth. The mechanisms by which these rhizobacteria enhance plant growth are multitudinous which include production of plant growth-regulating substances (PGRs), phytohormones, suppression of plant pathogens through antibiosis, bacteriocinogenic action, siderophore production, nitrogen fixation, mineralization of organic phosphorus, production of phytoalexins/flavonoids-like compounds, enhancement of mineral uptake, etc [44]. The cumulative effect of these complex interactions among plant roots and various microbial populations can result in plant growth promotion and or pathogenesis and decay. This section will focus on plant growth promotion by rhizobacteria either directly or indirectly. Rhizobacteria can stimulate growth by producing plant growth regulators known as phytostimulators in the absence of pathogens. Many phytostimulators are plant hormone analogues, meaning PGPR produce an identical or nearly identical compound that mimics the action of a plant hormone. These substances are usually light weight volatile organic compounds. Thus far, known phytostimulators include indole-acetic acid (IAA), gibberelic acid, cytokinins, and in some cases ethylene [44].The plant responses to PGPR have been excellently reviewed elsewhere [45].

\section{Rhizobium With Mycorrhiza And Host Plants}

Inoculation with an effective Rhizobium combination with AM fungi (Glomus sp.) had a variable effect on plant growth enhancement, nodulation, and N2 fixation. There are various studies in the literature describing many significant findings in the synergistic interaction between AMF and asymbiotic N2-fixing bacteria [46]; [47], [48]; [26]. The role of AM fungi as P suppliers to legume root nodules is of great relevance when a specific AM fungus, Rhizobacterium sp. known for effective nodulation and N2 fixation was found in a mycotrophic legume Anthyllis cytisoides in a Mediterranean semi-arid ecosystem in Spain. The strain Glomus intraaridices was found to be more effective with Rhizobium sp. NR 4, whereas Glomus coronatum was effective when co-inoculated with Rhizobium sp. NR9 strain. Research has provided evidence that the genetic pathway of AM symbiosis is shared in part by other root-microbe symbioses such as N2-fixing rhizobia [40]. Such specific interactions between AM fungi, Rhizobium, and PGPR have provided an insight into specific functional compatibility relationships between AMF and PGPR and their management when used as biofertilizers or biocontrol agents.

\section{1. rhizobium with mycorrhiza and host plant architecture}

Legume plants can form tripartite symbiotic associations with rhizobia and arbuscular mycorrhizal (am) fungi, but little is known about effects of co-inoculation with rhizobia and am fungi on plant growth, or their relationships to root architecture as well as nitrogen (n) and phosphorus (p) availability. it was reported that two soybean genotypes contrasting in root architecture were grown in a field experiment to evaluate relationships among soybean root architecture, amf colonization, and nodulation under natural conditions ([40]. Additionally, a soil pot experiment in greenhouse was conducted to investigate the effects of co-inoculation with rhizobia and AM Fungi on soybean growth, and uptake of $n$ and p. results indicated that there was a complementary relationship between root architecture and amf colonization in the field. The deep root soybean genotype had greater amf colonization at low $\mathrm{p}$, but better nodulation with high $\mathrm{p}$ supply than the shallow root genotype. a synergistic relationship dependent on $\mathrm{n}$ and $\mathrm{p}$ status exists between rhizobia and am fungi on 
soybean growth. Co-inoculation with rhizobia and am fungi significantly increased soybean growth under low $\mathrm{p}$ and/or low $\mathrm{n}$ conditions as indicated by increased shoot dry weight, along with plant $\mathrm{n}$ and $\mathrm{p}$ content.

\section{Am Fungi And Alleviation Of Soil Heavy Metal Stress}

Some heavy metal elements such as $\mathrm{Cu}, \mathrm{Fe}, \mathrm{Mn}, \mathrm{Ni}$ and $\mathrm{Zn}$ are essential for normal growth and development of plants. These metals are required in numerous enzyme- catalyzed or redox reactions, in electron transfer, and have structural function in nucleic acid metabolism [49]. In contrast, metals like $\mathrm{Cd}, \mathrm{Pb}, \mathrm{Hg}$, and As are not essential [49] and may be toxic to plants at every low concentration in soils. Heavy metals occur in terrestrial and aquatic ecosystems from both natural and anthropogenic sources, and are also emitted into the atmosphere. At high concentration heavy metals interfere with essential enzymatic activities by modifying protein structure or by replacing an essential element, resulting in deficiency symptoms. AM Fungi and Rhizobium are significant in remediation of contaminated soils as accumulation [50]. The external mycelium of AM fungi of AM Fungi allows for wider exploration of soils volumes by spreading beyond the root exploration zone [6], thus providing access quantities of heavy metals present in the Rhizosphere. High concentration of metals is also stored in mycorrhizal structures in the root and in fungal spores. AM Fungi and Rhizobium can also increase plant establishment and growth despite high level of soil heavy metals due to improved nutrition [51] associated with the same symbiosis. Significance of AM Fungi kin soil remediation has been recognized [15]. A vast amount of literature is available on the effects of mycorrhizal colonization on plants under heavy metal stress but contradictory observation and wide variation in results was reported [15].

\section{Improved Soil Quality}

Plant health and soil productivity are rooted in soil, and the quality of soils depends on the viability and diversity of its biota which determine the structures that support a stable and healthy agro- ecosystem. The goals of sustainability in agriculture could be viewed broadly as "maximum plant production with a minimum of soil loss"'. In this scenario of balanced agro- system inputs and outputs, the relevance of mycorrhizal endophytes has been described as that of a fundamental link between plants and soil [41]. They have showen how the affinity between mycorrhizae along with Rhizobium and soil aggregates vary with root characterizes, with the intensity of root colonization, and with the quantum of soil mycelium associated with the root system.

\section{Resilience Of Problematic Soils}

Since the advent of civilization, the fertile top soil has been degrading due to various environmental and ecological factors like saline and Sodic soils, eroded soils, industrial waste lands, soils from mining regions, degraded forest lands, sands dunes and deserts etc. In these soils the native vegetation and animal communities scarred to endangered. Therefore, rehabilitation of these soils in a global problem and the afforestation and other agricultural activities are in progress but only limited success has been achieved. AM Fungi have been found to grow up to salinity of $12 \mathrm{dSm}^{-1}$ electrical conductivity and increased the uptake of $\mathrm{P}, \mathrm{N}, \mathrm{S}$ and microorganisms in crop [52]. The letter could be due to high metal sorption capacity of these fungi, which could filter metal ions during uptake [52]. However, the competitivity of such metal tolerant AM fungi IN the field is often not known and should be investigated.

\section{Conclusion}

The aim of the present review was to investigate the effect of Rhizobium and Arbuscular Mycorrhizal fungi inoculation, both individually and in combination on crop growth and chemical properties of Rhizospheric soils in high plants. Dominant Arbuscular Mycorrhizal fungi, either alone or in combination with Rhizobium inoculants, can establish a symbiosis with legumes and other high major plants, which results in growing better and producing more either under laboratory or field conditions. Recently, the review showed that treatments with Arbuscular Mycorrhizal Fungi and Rhisobium significantly improve root morphology, the whole crop growth as well as soil properties in rhisospheric soils. The above reviewed studies have revealed that common host genes are involved in both the Rhizobial and Mycorrhizal interactions. This finding has an important implication, since in contrast to Rhizobium, AM fungi have the ability to interact with a wide range of higher plants and both combined together influence significantly the growth, root morphology and chemical properties of the rhisospheric soils of compatible plants. The beneficial effects of the rhizobacteria and AM Fungi in enhancing root development associated with increase in nodule biomass by native as well as co-inoculated Rhizobium strains are well documented. Various studies have also provided an evidence of different mechanisms by which there is an increase in crop productivity and the disease suppressive ability of these microorganisms in rhizosheric soils. There is still not enough data to suggest the establishment of the newly 
isolated rhizobacterial strains and AM Fungi in the rhizosphere, but further studies using genetically marked strains should make it possible to determine their exact role in rhizosphere establishment.

\section{Acknowledgements}

I thank Dr. Balkrishna Sopan Bhople and Dr. Anil Kumar for critical reading of the manuscript. This article is supported by the Department of Agriculture, School of Agriculture in Lovely Professional University, India.

\section{Journal Papers:}

\section{References}

[1]. Gianinazzi-Pearson, V. (1996) Plant cell responses to arbuscular mycorrhizal fungi: getting to the roots of the symbiosis. Plant Cell, 8, 1871-1883.

[2]. Mylona,P., Pawlowski,K. and Bisseling,T. (1995) Symbiotic nitrogen fixation. Plant Cell, 7, 869-885.

[3]. Chalk, P. M. R. de F. Souza, S. Urquiaga, B. J. R. Alves and R. M. Boddey. 2006. The role of arbuscular mycorrhiza in legume symbiotic performance. Soil Biol. Bioch. 38: 2944-2951

[4]. Harrison,M.J. (1996, 1997, Guinel and Geil, 2002) The arbuscular mycorrhizal symbiosis: an underground association. Trends Plant Sci., 2, 54-60.

[5]. Doyle RJ, Lee NC. (1986). Microbes, warfare, religion and human institutions. Can J Microbiol; 32:193-200.

[6]. Hayat R, Safdar Ali S, Amara U, Khalid R, Ahmed I (2010). Soil beneficial bacteria and their role in plant growth promotion: a review. Ann Microbial 60:579-598.

[7]. Saleem M, Arshad M, Hussain S, Bhatti AS (2007) Perspective of plant growth promoting rhizobacteria (PGPR) containing ACC deaminase in stress agriculture. J Ind Microbiol Biotechnol 34:635-648

[8]. Babalola (2010). Beneficial bacteria of agricultural importance. Biotechnol Lett 32:1559-1570

[9]. Berg, G. (2009) Plant-microbe interactions promoting plant growth and health: perspectives for controlled use of microorganisms in agriculture. Apply Microbiol Biotechnol 84:11-18

[10]. Gerdemann, J. W. \& Nicolson, T. H. (1963). Spores of mycorrhizal Endogone species extracted from soil by wet sieving and decanting. Transactions of the British Mycological Society, 46, 235.

[11]. Giovannetti,M., Avio,L., Sbrana,C. and Citernesi,A.S. (1993) Factors affecting appressorium development in the vesiculararbuscular mycorrhizal fungus Glomus mosseae (Nicol. \& Gerd.). New Phytol., 123, 115-122.

[12]. Khan AG. Role of soil microbes in the rhizospheres of plants growing on trace lement contaminated soils in phytoremediation. $\mathrm{J}$ Trace Elem Med Biol. 2005;18(4):355-364. doi: 10.1016/j.jtemb.2005.02.006.

[13]. Nagahashi,G. and Douds,D.D. (1997) Appressorium formation by AM fungi on isolated cell walls of carrot roots. New Phytol., 136, 299-304.

[14]. Graves, Y. D., N. K. Watkins, A. H. Fitter, D. Robinson, and C. Scrimgeour. 1997. Intraspecific transfer of carbon between plans linked by a common mycorrhizal network. Plant and Soil 192:153-159.

[15]. Tommerup, I.C.,Abbott, L.K. (1981). Prolonged survival and viability of VA Mycorrhizal hyphae after root death. Soil biochemistry 13: 431-433.

[16]. Schweiger, P. F., A. D. Robson, and N. J. Barrow. 1995. Root hair length determines beneficial effect of a Glomus species on shoot growth of some pasture species. New Phytologist 131: 247-254

[17]. Hook, J.E, Arkinson D. 1995. Vesicular- Arbusclar fungi induced alteration in popular root system morphology, plant and soil. 195: 207-214

[18]. Mohammad A, Mitra B, Khan AG. Effects of sheared-root inoculum of Glomus intraradices on wheat grown at different phosphorus levels in the field. Agric Ecosystems \& Environment. 2004; 103 (1):245-249.

[19]. Andrade G, Mihara KL, Linderman RG, Bethlenfalvay GJ. Bacteria from the rhizosphere and hyphorhizosphere soils of different arbuscular mycorrhizal fungi. Plant and Soil. 1997; 192(1):71-79.

[20]. Long,S.R. (1996) Rhizobium symbiosis: Nod factors in perspective. Plant Cell, 8, 1885-1898.

[21]. Carlson,R.W., Price,N.P.J. and Stacey,G. (1994) The biosynthesis of rhizobial lipo-oligosaccharide nodulation signal molecules. Mol. Plant Microbe Interact. 7, 684-695.

[22]. Niebel,A., Bono,J.J., Ranjeva,R. and Cullimore,J.V. (1997) Identification of a high affinity binding site for lipooligosaccharidic NodRm factors in microsomal fraction of Medicago cell suspension cultures. Mol. Plant Microbe Interact. 10, $132-134$.

[23]. Turgeon,B.G. and Bauer,W.D. (1985) Ultrastructure of infection-thread development during infection of soybean by Rhizobium japonicum. Planta, 163, 328-349.

[24]. Ardourel,M., Demont,N., Debelle',F., Maillet,F., De Billy,F., Prome',J.C., De'narie', J. and Truchet,G. (1994) Rhizobium meliloti lipooligosaccharide nodulation factors: different structural requirements for bacterial entry into target root hair cells and induction of plant symbiotic developmental responses. Plant Cell, 6, 1357-1374.

[25]. Akhtar MS, Siddiqui ZA (2008a). Biocontrol of a root-rot disease complex of chickpea by Glomus intraradices, Rhizobium sp. and Pseudomonas straita. Crop Protec 27:410-417

[26]. Kathiresan K, Selvam MM (2006). Evaluation of beneficial bacteria from mangrove soil. Botanica Marina 49(1): 86-88.

[27]. Nasr H, Ghorbel MH, Dommergues YR (2006) Symbiotic interactions of Acacia cyanophylla with soil indigenous rhizobia . J. Plant Physiol., 1(1): 54-64.

[28]. Behl RK, Sharma H, Kumar V, Narula N. Interactions among mycorrhiza, Azobacter chroococcum and root characteristics of wheat varieties. J Agron \& Crop Sci. 2003; 189(3):151-155.

[29]. Ahmad F, Ahmad I, Khan MS (2008) Screening of free-living rhizospheric bacteria for their multiple plant growth promoting activities. Microbiol Res 163:173-181

[30]. Bakker PA, Pieterse CM, van Loon LC (2007) Induced systemic resistance by fluorescent Pseudomonas spp. Phytopathology 97:239-243

[31]. Barea JM, Andrade G, Bianciotto VV, Dowling D, Lohrke S, Bonfante P, O'Gara F, Azcon- Aguilar C (1998) Impact on arbuscular mycorrhiza formation of pseudomonas strains used as inoculants for biocontrol of soil-borne fungal plant pathogens. Appl Environ Microbiol 64:2304-2307

[32]. Barea JM, Azcon R, Azcon-Aguilar C (2002) Mycorrhizosphere interactions to improve plant fitness and soil quality. Antonie Van Leeuwenhoek 81:343-351 
[33]. Barea JM, Pozo MJ, Azcon R, Azcon-Aguilar C (2005) Microbial co-operation in the rhizosphere. J Exp Bot 56:1761-1778

[34]. Gohre, V., and Poszkowski, V., 2006, Contribution of the Arbuscular Myccorrhizal Symbiosis to heavy metal Phytoremediation. Planta 223: 1115-1122

[35]. Jamal, A., Ayub, N., Usman, M., and Khan, A.G., 2002, AM Fungi enhance Zinc and Nickel uptake from contaminated soil by Soybean and Lentil. Int. J. Phytoremed. 4: 205-221

[36]. Taylor, J., and Harrier, L.A., 2001, A comparison of Development and Mineral Nutrition of micro propagated Fragari* ananassa Cv. Elvira (Strawberry) when colonized by nine species of Arbuscular mycchorizal Fungi. App. Soil Eco. 18:2005-2015.

[37]. Joner E.J. Briones R, Leyval C(2000) Metal binding of Arbiscular mycorrhizal fungi. Plant Soil 226:228-134

\section{Books:}

[38]. Berta,G. Fusconi, A., Trotta A., Sconnermi, S. 1900. Morphogenetic modifications induced by the mychorrhizal fungus in the ro ot system (52)

[39]. Allen MF. Mycorrhizal Functioning: An Integrative Plant-Fungal Process ( Routledge, NY: Chapman \& Hall Inc.; 1992. p. 534.)

[40]. Spaink,H.P., Kondorosi,A. and Hooykaas,P.J.J. The Rhizobiaceae (Kluwer Academic Publishers, Dordrecht, The Netherlands., 1998)

[41]. Mirrer, R.M., and Jastrow, J.D., Mychorrhizal Fungi influence soil structure (. PP 3-18., 2000)

\section{Chapters in Books:}

[42]. Khan AG. The Handling of Microbes. In: Wong MH, Bradshaw AD, editors. The Restoration and Management of Derelict Land (Modren Approaches. Singapore: World Scientific Publishing; 2002.) pp. 149-160

[43]. Ray RC, Ward OP, Singh A, Isobe S Commercialization of microbial biotechnology in horticulture: summary, outlook of achievements, constraints and prospects. In: Ray RC, Ward OP (eds) Microbial biotechnology in horticulture, vol 3. (Science, New Hampshire, 2008). pp 341-365

[44]. Linderman RG, Paulitz TC. Mycorrhizal-rhizobacterial Interactions. In: Hornb D, editor. Biological Control of Soil-borne Plant Pathogens (Wallingford: CAB International; 1990) pp. 261-283.

[45]. Adholeya A, Johri RN Effect of Glomus coledonium and Rhizobium inoculation on greengram (Vigna radiata L. Wilczek). In: Singh R, Nainawatee HS, Sawney SK (eds) Proceedingsof national symposium on current status of biological nitrogen fixation research (HaryanaAgricultural University, Hisar, India, 2003) p 173

[46]. Sylvia DM, Jarstfer AG. Production of Inoculum and Inoculation with Arbuscular Mycorrhizal Fungi. In: Robson AD, Abbott LK, Malajczuk N, editors. Management of Mycorrhizas in Agricture, Horticulture and Forestry (Dordrecht: Kluwer; 1994) pp. 231-238.

[47]. Azcon-Aguilar C, Jaizme-Vega MC, Calvet C. The Contribution of Arbuscular Mycorrhizal Fungi to the Control of Soil-borne Plant Pathogens. In: Gianinazzi S, Schuepp H, editors. Mycorrhizal Technology: from Genes to Bioproducts-Achievements and Hurdles in Arbuscular Mycorrhiza Research. Basel ( Birkhauser; 2002 ) pp. 187-198.

[48]. Barea JM. Rhizosphere and Mycorrhizae of Field Crops. In: Toutant P, Balazs E, Galante E, et al., editors.Biological Resource Management, Connecting Science and Policy (OECD) (Berlin, Heidelberg, New York: INRA and Springer; 2000)

[49]. Dudeja SS, Narula N. Molecular diversity of root nodule forming bacteria. In: Khachatourians GG, Arora DK, Rajendran TP, Srivastava AK (eds) Agriculturally important microorganisms, vol II (Academic World International, Bhopal, India 2008) pp 1-24

[50]. Peterson RL, Guinel FC (2000). The use of plant mutants to study regulation of colonization by AM fungi. In: Kapulnik KDY, Douds DD (eds) Arbuscular mycorrhizas: physiology and function (Kluwer, Dordrecht,) pp 147-171

\section{Proceedings Papers:}

[51]. Schultz PA, Miller RM, Jastrow JD, Rivetta CV, Bever JD (2001). Evidence of a mycorrhizal mechanism for the adaptation of Andropogon gerardii (Poaceae) to high- and low-nutrient prairies. Am J Bot 88:1650-1656 